\title{
Evaluation of the rapid and slow maxillary expansion using cone-beam computed tomography: a randomized clinical trial
}

\author{
Juliana da S. Pereira' ${ }^{1}$, Helder B. Jacob², Arno Locks³, Mauricio Brunetto ${ }^{4}$, Gerson L. U. Ribeiro ${ }^{5}$
}

DOI: http://dx.doi.org/10.1590/2177-6709.22.2.061-068.oar

\begin{abstract}
Objective: The aim of this randomized clinical trial was to evaluate the dental, dentoalveolar, and skeletal changes occurring right after the rapid maxillary expansion (RME) and slow maxillary expansion (SME) treatment using Haas-type expander. Methods: All subjects performed cone-beam computed tomography (CBCT) before installation of expanders $\left(\mathrm{T}_{1}\right)$ and right after screw stabilization $\left(\mathrm{T}_{2}\right)$. Patients who did not follow the research parameters were excluded. The final sample resulted in 21 patients in RME group (mean age of 8.43 years) and 16 patients in SME group (mean age of 8.70 years). Based on the skewness and kurtosis statistics, the variables were judged to be normally distributed and paired t-test and student t-test were performed at significance level of 5\%. Results: Intermolar angle changed significantly due to treatment and RME showed greater buccal tipping than SME. RME showed significant changes in other four measurements due to treatment: maxilla moved forward and mandible showed backward rotation and, at transversal level both skeletal and dentoalveolar showed significant changes due to maxillary expansion. SME showed significant dentoalveolar changes due to maxillary expansion. Conclusions: Only intermolar angle showed significant difference between the two modalities of maxillary expansion with greater buccal tipping for RME. Also, RME produced skeletal maxillary expansion and SME did not. Both maxillary expansion modalities were efficient to promote transversal gain at dentoalveolar level. Sagittal and vertical measurements did not show differences between groups, but RME promoted a forward movement of the maxilla and backward rotation of the mandible.
\end{abstract}

Keywords: Maxillary expansion. Haas-type. Cone-beam computed tomography.

\begin{abstract}
Objetivo: o objetivo do presente ensaio clínico randomizado foi avaliar as transformações dentárias, dentoalveolares e ósseas que ocorrem imediatamente após o tratamento com expansão rápida da maxila (ERM) e lenta (ELM) usando expansores do tipo Haas. Métodos: todos os indivíduos foram submetidos a tomografias computadorizadas de feixe cônico (TCFC) antes da colocação dos expansores $\left(\mathrm{T}_{1}\right)$ e imediatamente após a estabilização do parafuso $\left(\mathrm{T}_{2}\right)$. Os pacientes que não seguiram os parâmetros da pesquisa foram excluídos. A amostra final constou de 21 pacientes no grupo ERM (idade média de 8,43 anos) e 16 no grupo ELM (idade média de 8,7 anos). Com base em estatística de assimetria e curtose, as variáveis foram consideradas de distribuição normal, e os testes $t$ pareado e $t$ de Student foram realizados, com nível de significância de 5\%. Resultados: o ângulo intermolares mudou significativamente devido ao tratamento, e o grupo ERM apresentou maior inclinação vestibular do que o grupo ELM. O grupo ERM mostrou alterações significativas em outras quatro medidas devido ao tratamento: a maxila apresentou deslocamento anterior e a mandíbula, rotação posterior; no nível transversal, houve tanto alterações ósseas quanto dentoalveolares significativas, devido à expansão maxilar. O grupo ELM apresentou alterações significativas devido à expansão maxilar. Conclusões: apenas o ângulo intermolares apresentou diferença significativa entre as duas modalidades de expansão maxilar, com maior inclinação vestibular no grupo ERM. A ERM resultou, também, em expansão maxilar óssea, ao contrário da ELM. As duas modalidades de expansão maxilar promoveram, de forma eficiente, um ganho transversal em nível dentoalveolar. As medidas sagitais e verticais não apresentaram diferenças entre os grupos, mas a ERM promoveu o deslocamento anterior da maxila e a rotação posterior da mandíbula.
\end{abstract}

Palavras-chave: Expansão maxilar. Aparelho tipo Haas. Tomografia computadorizada de feixe cônico.

${ }^{1}$ Private practice, Florianópolis, SC, Brazil.

${ }^{2}$ Assistant Professor, Department of Orthodontics, The University of Texas

Health Science Center at Houston School of Dentistry, Houston-TX, USA.

${ }^{3}$ Federal University of Santa Catarina, Department of Orthodontics,

Florianópolis, SC, Brazil.

${ }^{4}$ Private practice, Curitiba, PR, Brazil.

${ }^{5}$ Federal University of Santa Catarina, Department of Orthodontics,

Florianópolis, SC, Brazil.

Submitted: May 18, 2016 - Revised and accepted: October 09, 2016 " The authors report no commercial, proprietary or financial interest in the products or companies described in this article.
How to cite this article: Pereira JS, Jacob HB, Locks A, Brunetto M, Ribeiro GLU. Evaluation of the rapid and slow maxillary expansion using cone-beam computed tomography: a randomized clinical trial. Dental Press J Orthod. 2017 Mar-Apr;22(2):61-8. DOI: http://dx.doi.org/10.1590/2177-6709.22.2.061-068.oar

» Patients displayed in this article previously approved the use of their facial and intraoral photographs.

Contact address: Gerson Luiz Ulema Ribeiro

Departamento de Ortodontia, Universidade Federal de Santa Catarina,

Campus Universitário Trindade - Florianópolis/SC, Brasil - CEP: 88.040-900

E-mail: gerson.orto@hotmail.com 


\section{INTRODUCTION}

Crossbite has been related to $7 \%$ of the American population in children and it does not self-correct over time, increasing to $9.5 \%$ of the adult population. ${ }^{1}$ Maxillary expansion is a widely accepted procedure performed by orthodontists to correct the posterior crossbite and transverse maxillary deficiency, and early treatment has been performed to correct the transversal discrepancy avoiding future extraction. ${ }^{2}$

There are many kinds of maxillary expansion appliances and various recommended expansion rates, which can result in rapid maxillary expansion (RME) or slow maxillary expansion (SME) ${ }^{3,4}$ Using jackscrew expanders, RME can be usually defined as two turns per day while SME uses one turn after every second day or greater interval. ${ }^{5}$ Each treatment modality (RME or SME) has advantages and disadvantages.

Due to the diversity of methodologies, such as appliance design and activation, there is no consensus in the literature regarding the dental and skeletal effects immediately after RME and SME., ${ }^{3,4}$ To provide, for the first time, comparisons between RME and SME using Haas-type expander analyzed by CBCT, this randomized clinical trial was designed to evaluate changes that occur right after the active treatment. The specific aims were to evaluate the dentoalveolar buccal tipping and skeletal changes in sagittal, vertical and transverse dimensions immediately after RME and SME in patients with mixed dentition, through CBCT.

\section{MATERIAL AND METHODS}

This randomized clinical trial was performed at the Federal University of Santa Catarina and approved by the ethics committee of the university (\#1834/12). Subjects were selected between July 2007 and October 2011. Informed consent was obtained from the parents of all patients who agreed to participate in this study. The inclusion criteria were as follows: transverse maxillary deficiency, inter-transitional period of mixed dentition, ages between 7 and 10 years, and absence of metallic restorations on the upper first molars.

The sample comprised 57 children who were divided into two groups. For allocation of the participants, a computer-generated list of random numbers was used (Microsoft Excel, Microsoft Corp. Richmond, WA). All patients used the same tooth-tissue-borne palatal expander recommended by Haas (Fig 1). ${ }^{6}$ Each appliance included a screw-type expander with a maximum aperture of $11.0 \mathrm{~mm}$ (Dentaurum, Inspringen, Germany) and bands on the first deciduous and first permanent molars. The screw was opened exactly $8 \mathrm{~mm}$ in both groups of subjects. Patients who did not follow the protocol of activation correctly, failed in cementing the expander, did not return for the control appointment and/or within 7 days of the stabilization were excluded from the data analysis.

Group 1 initially consisted of 28 patients (16 girls and 12 boys, mean age of 8.18 years) who were treated by RME (approximately three weeks of treatment time), with $1 / 2$ turn $(0.4 \mathrm{~mm})$ per day and activated with a full turn on the first day. Only 21 of these patients remained in the study (13 girls and 8 boys, mean age of 8.43 years). Group 2 initially consisted of 29 patients (18 girls and 11 boys, mean age of 8.43 years) who were treated by SME (approximately 20 weeks of treatment time), with a $1 / 2$ turn $(0.4 \mathrm{~mm})$ per week (1/4 turn on Tuesday and $1 / 4$ on Friday) with a $1 / 2$ turn on the first day. Only 16 patients remained in this group ( 8 girls and 8 boys, mean age of 8.70 years) throughout the study. Patients were followed weekly to control the activation protocol. After expansion, the devices were stabilized with $0.12-\mathrm{mm}$ ligature wire (Morelli, Sorocaba, Brazil).

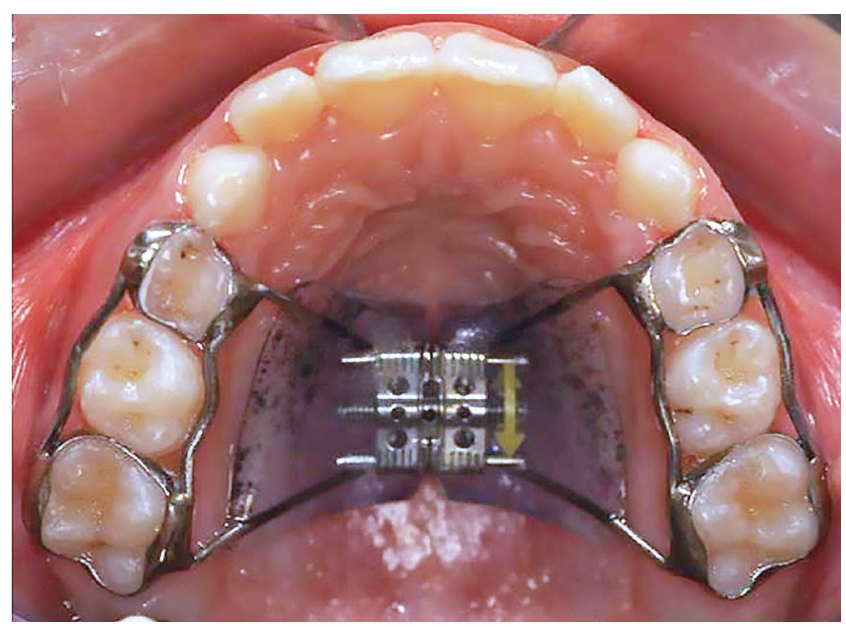

Figure 1 - Occlusal view of the Haas-type expander used in the study. 

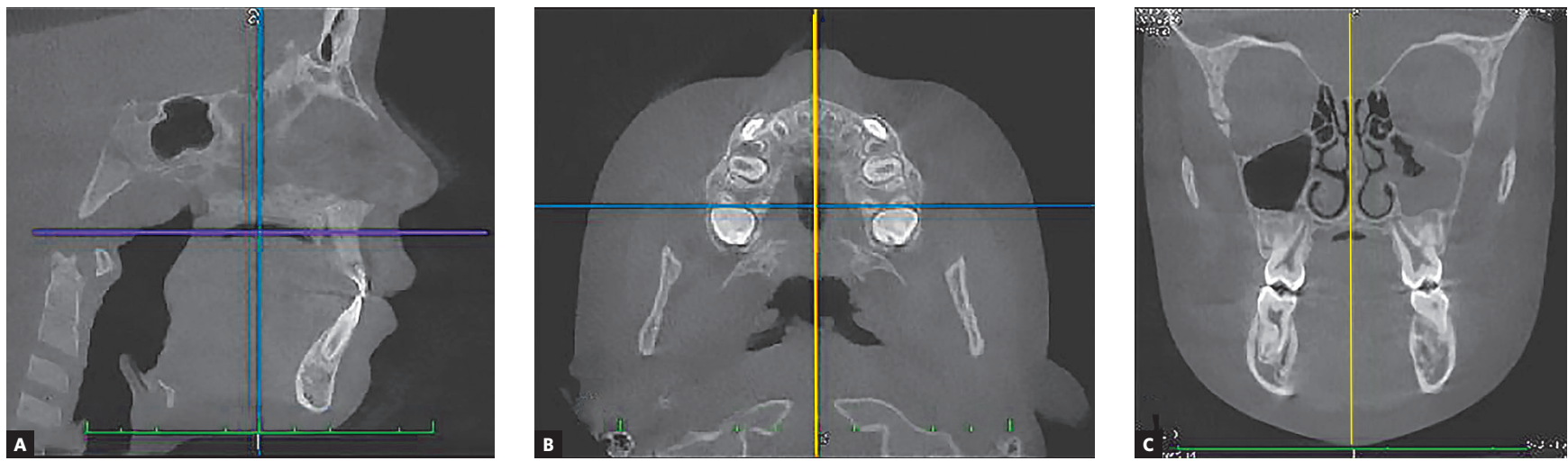

Figure 2 - A) Sagittal view: coronal plane (blue line) and axial plane (purple line) at A-point level. B) Axial view: sagittal plane (yellow line) and coronal plane (blue line) at the center of the first molar palatal roots at furcation level. C) Coronal view: coronal plane and sagittal plane (yellow line) at the furcation level of the maxillary first molars.

All patients were subjected to CBCT between 1 and 7 days prior to installation of expanders $\left(\mathrm{T}_{1}\right)$ and after the screw stabilization $\left(\mathrm{T}_{2}\right)$. The i-CAT (Imaging Sciences International, Hatfield, PA) was used to obtain CBCT images with the scans performed at $120 \mathrm{Kv}, 20 \mathrm{~mA}$, and scan time of 14.7 seconds with $0.25-\mathrm{mm}$ isotropic voxel resolution. The data for each patient were reconstructed with $0.5-\mathrm{mm}$ slice thickness and the DICOM (digital imaging and communications in medicine) files were assessed by using the Osirix Medical Imaging Software 32-bit (Open-Source, Osirix Medical Imaging Software, www.osirix-viewer.com). ${ }^{7}$ All digitalization was performed by a blinded examiner.

To perform the analysis, Frankfurt Horizontal Plane (Sagittal view), Midsagittal plane (Axial view), and the Coronal plane (Coronal view) were used to set the head orientation (Fig 2). The linear and angular measurements were made in a Multiplanar Reconstruction to the nearest $0.01 \mathrm{~mm}$ and $0.01^{\circ}$, respectively. The analyses of the transverse changes were performed with $0.5-\mathrm{mm}$ slice thickness. Ten measurements (Table 1) were performed before and after treatment.

Seven measures analyzed the sagittal and vertical changes of the maxilla performing at the Midsagittal Plane (Fig 3). A perpendicular line related to SellaNasion line centered on Sella was used to measure the anterior position of the maxilla and the angle between the maxilla and the cranial base. Vertical position of the maxilla was measured using a perpendicular projection from the ANS to cranial base. A 1.5-mm slice thickness was used for difficulties in visualization of A-point after maxillary expansion procedure, due to the low density of bone tissue in the median suture.

Transversal changes were performed at the coronal plane (Fig 4). The first molars were positioned using the axial view and the entire palatal root could be seen in the sagittal view. Using the coronal view, the distance between the mesial palatal cusps was measured as a line orthogonal to Frankfurt Horizontal Plane, cutting the geometric center of the right and left upper first molars palatal roots, at the furcation level. To measure the molar tipping, the best fit of the distal buccal cusp and palatal root of both sides was used in the coronal view.

\section{Statistical analysis}

All measurements in ten patients (randomly selected from each group) were performed twice in one-month interval determining the intraexaminer reliability of the measurements. The intraclass correlation coefficients (ICC) showed a high degree of reliability (Table 2). Paired t-test showed no statistically significant differences between replicates. Dahlberg's ${ }^{8}$ method error (double determination method) ranged between 0.12 and $0.65 \mathrm{~mm}$ for the landmarks. Based on the skewness and kurtosis statistics, the variables were judged to be normally distributed. The mean and standard deviation for each parameter were calcu- 


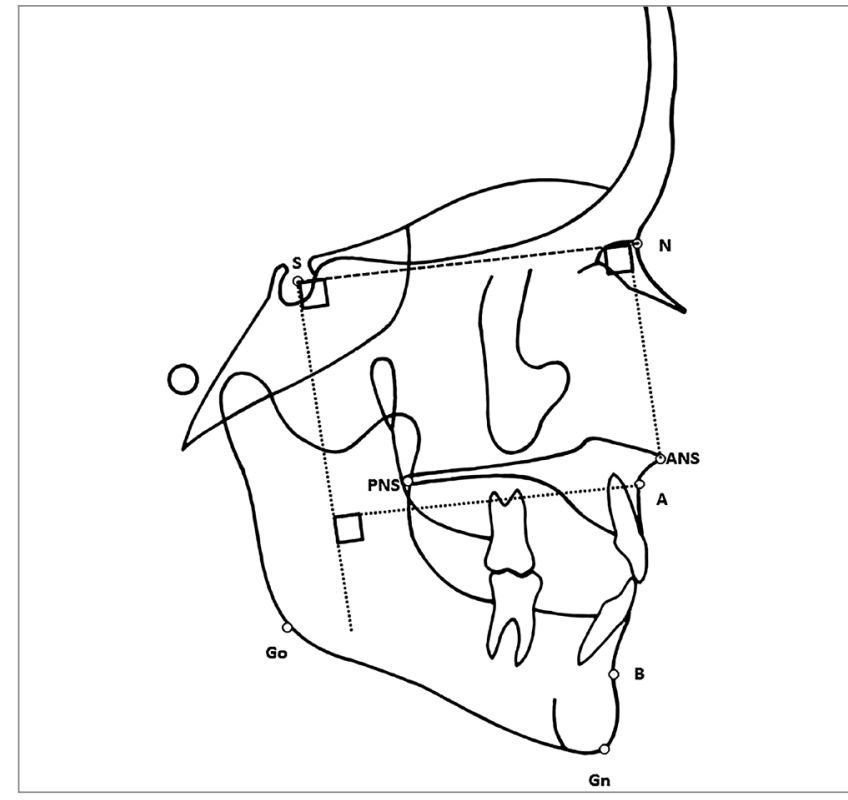

Figure 3 - Landmarks used to perform the measurements in the sagittal view Special attention is given to show how some of the measures were obtained i.e. the palatal plane angle, anterior (A-point) and vertical (ANS) positions of the maxilla.

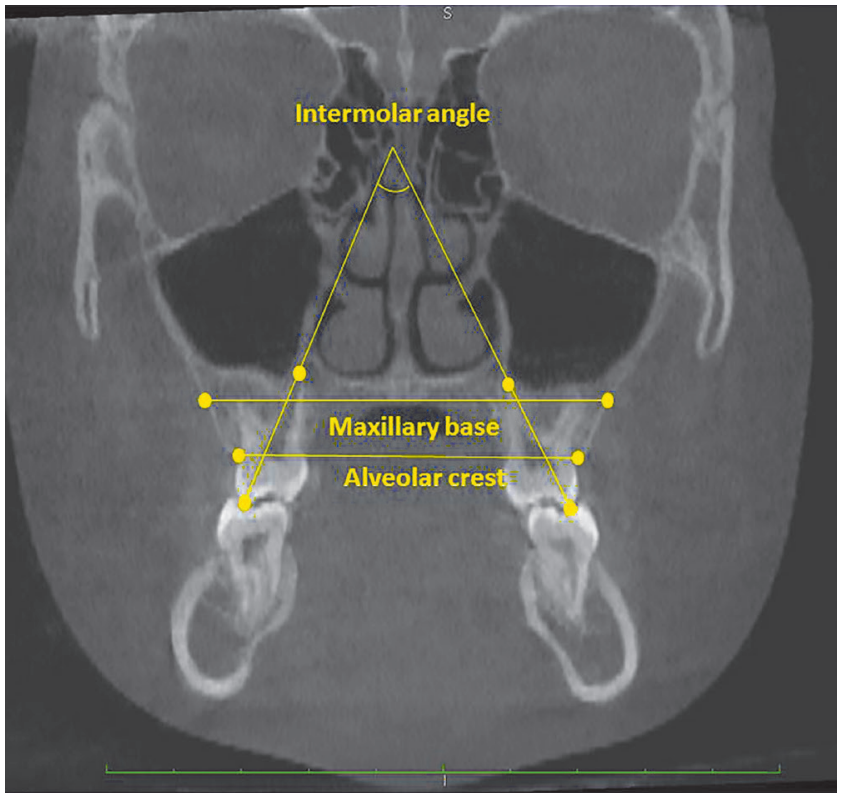

Figure 4 - Landmarks and the three measurements analyzed in the coronal view.

Table 1 - Definition of the landmarks and measurements used to evaluate differences between groups.

\section{Abbreviation}

\section{Description}

\section{Landmarks}

S Sella: the center of hypophyseal fossa

N Nasion: the junction of the nasal and frontal bones

ANS Anterior nasal spine: the most anterior part of the maxilla

PNS Posterior nasal spine: the most posterior part of the maxilla

A A-point: junction of the maxillary dentoalveolar and basal bone

B B-point: junction of the mandibular dentoalveolar and basal bone

Gn Gnathion: most outward and everted point of the mandibular symphysis

Go Gonion: middle of outer curvature between ramus and corpus of the mandible

Sagittal

SNA Angle between S-N line and N-A line.

SNB Angle between S-N line and N-B line.

ANB Angle between SNA and SNB

SNperp-A Linear distance of the orthogonal projection of the A-point to SN line measured from S.

\section{Vertical}

SNperp.PP Angle between orthogonal line from S-N line centered on S palatine plane (line between ANS and PNS)

SN-ENA Orthogonal distance to S-N line from ANS

SN.GoGn Angle between S-N line and mandibular plane (line between Go and Gn)

\section{Transverse}

Linear distance from the right side intersection of the tangent to the lowest point of the contour of the nasal cavity and the maxillary alveolar border on the left side.

Alveolar crest Linear distance of the lowest point of the alveolar process of the right side to the left side

Intermolars angle Angle between the apex of the palatal root and the tip of the buccal cusp of the maxillary first molar line of right and left sides 
lated and paired t-tests were used to evaluate changes over time. The student t-test was used to compare the groups. A probability level of 5\% was used to determine statistical significance. The data obtained from all measurements were processed with SPSS software (version 22.0, IBM-SPSS Corporation, EUA).

\section{RESULTS}

In RME group, 7 individuals were excluded from analysis because 5 failed to meet the activation protocol or did not return for control appointments, and on 2 the device became loose in the anchor teeth. In SME group, 13 individuals were excluded because

Table 2 - Intraclass Correlation Coefficient (ICC) with range minimum and maximum) from measurements.

\begin{tabular}{|c|c|}
\hline Parameters & ICC (min.; max.) \\
\hline \multicolumn{2}{|c|}{ Sagital } \\
\hline SNA & $0.99(0.97 ; 0.99)$ \\
\hline SNB & $0.99(0.99 ; 1.00)$ \\
\hline ANB & $0.99(0.97 ; 1.00)$ \\
\hline SNperp-A & $0.99(0.99 ; 1.00)$ \\
\hline \multicolumn{2}{|c|}{ Sagittal } \\
\hline SNperp.PP & $0.96(0.89 ; 0.98)$ \\
\hline SN-ENA & $0.89(0.72 ; 0.96)$ \\
\hline SN.GoGn & $0.97(0.93 ; 0.99)$ \\
\hline \multicolumn{2}{|c|}{ Transverse } \\
\hline Skeletal width & $0.97(0.92 ; 0.99)$ \\
\hline Dentoalveolar width & $0.89(0.72 ; 0.96)$ \\
\hline Intermolar angle & $0.97(0.92 ; 0.99)$ \\
\hline
\end{tabular}

3 did not make the CBCT within seven days of stabilization, on 6 the appliance failed to be cemented on the anchor teeth, 3 did not respect the activation protocol, and 1 did not return to control appointments. SME group had greater difficulty in control of the activation schedule due to longer use of the activation expander (20 weeks) than RME group (3 weeks).

Parametric test revealed significant $(p<0.05)$ group differences prior to treatment for only one of the measures (Table 3). Compared to SME, the RME patients initially had larger maxillary base $(\approx 2 \mathrm{~mm})$.

In general, RME promoted greater changes than SME, but just one showed significant difference between groups (Fig 5). The treatment produced significant $(p<0.05)$ differences in 5 and 2 of each 10 measurements for the RME and SME groups, respectively (Table 4). Although the forward movement of the A-point is the same (approximately $0.5 \mathrm{~mm}$ ) for both groups, only RME group showed significant difference over treatment time. The mandibular plane angle increased in both groups, but just RME group showed significant difference due to treatment. Skeletal maxillary base showed greater transverse changes after treatment for RME group. Dentoalveolar transverse changes (approximately $5 \mathrm{~mm}$ in both groups) and intermolar angle $\left(\approx 21^{\circ}\right.$ and $\approx 9^{\circ}$ for $\mathrm{RME}$ and SME groups, respectively) increased in both groups during treatment time. Interestingly, the molar tipping was the only measurement which showed difference between two types of treatment approach.

Table 3 - Descriptive pretreatment linear and angular measurements of the treated patients using RME and SME.

\begin{tabular}{|c|c|c|c|c|c|c|}
\hline \multirow[b]{2}{*}{ Parameters } & \multicolumn{2}{|c|}{ RPE } & \multicolumn{2}{|c|}{ SPE } & \multirow[b]{2}{*}{ Diff. } & \multirow[b]{2}{*}{ p-value } \\
\hline & Mean & SD & Mean & SD & & \\
\hline \multicolumn{7}{|c|}{ Sagittal } \\
\hline SNA (degrees) & 81.50 & 3.04 & 83.01 & 3.48 & -1.51 & 0.168 \\
\hline SNB (degrees) & 77.29 & 3.27 & 78.57 & 3.79 & -1.28 & 0.279 \\
\hline ANB (degrees) & 4.14 & 2.97 & 4.40 & 2.58 & -0.26 & 0.784 \\
\hline SNperp-A (mm) & 55.01 & 3.55 & 56.01 & 4.11 & -1.00 & 0.435 \\
\hline \multicolumn{7}{|c|}{ Vertical } \\
\hline SNperp.PP (degrees) & 97.16 & 4.01 & 97.16 & 3.30 & $<.01$ & 0.999 \\
\hline SN-ENA (mm) & 44.90 & 2.49 & 44.27 & 2.86 & 0.64 & 0.476 \\
\hline SN.GoGn (degrees) & 34.81 & 5.08 & 35.01 & 6.06 & -0.19 & 0.917 \\
\hline \multicolumn{7}{|c|}{ Transverse } \\
\hline Skeletal width (mm) & 60.13 & 3.07 & 58.14 & 1.78 & 1.98 & 0.027 \\
\hline Dentoalveolar width (mm) & 53.08 & 2.08 & 52.72 & 2.61 & 0.36 & 0.646 \\
\hline Intermolar angle (degrees) & 69.19 & 10.20 & 70.87 & 11.71 & -1.67 & 0.646 \\
\hline
\end{tabular}

Boldface indicates significance $(p<0.05)$ 
Table 4 - Comparison of changes between treated patients with RME and SME groups, with T-test.

\begin{tabular}{|c|c|c|c|c|c|c|c|c|}
\hline \multirow[b]{2}{*}{ Parameters } & \multicolumn{3}{|c|}{ RPE Group } & \multicolumn{3}{|c|}{ SPE Group } & \multirow[b]{2}{*}{ Dif. } & \multirow[b]{2}{*}{ valor-p } \\
\hline & Mean & SD & Mean & SD & Diff. & Prob. & & \\
\hline \multicolumn{9}{|c|}{ Sagittal } \\
\hline SNA (degrees) & 0.41 & 1.40 & 0.194 & -0.10 & 0.86 & 0.657 & 0.51 & 0.210 \\
\hline SNB (degrees) & -0.47 & 1.33 & 0.120 & -0.09 & 1.17 & 0.770 & -0.38 & 0.366 \\
\hline ANB (degrees) & 0.89 & 2.20 & 0.078 & -0.04 & 1.01 & 0.884 & 0.93 & 0.126 \\
\hline SNperp-A (mm) & 0.51 & 0.89 & 0.016 & 0.52 & 2.38 & 0.397 & -0.01 & 0.994 \\
\hline \multicolumn{9}{|c|}{ Vertical } \\
\hline SNperp.PP (degrees) & -0.45 & 2.35 & 0.391 & -0.10 & 1.66 & 0.808 & -0.35 & 0.618 \\
\hline $\mathrm{SN}-\mathrm{ENA}(\mathrm{mm})$ & 0.88 & 2.58 & 0.136 & 0.53 & 1.43 & 0.164 & 0.35 & 0.628 \\
\hline SN.GoGn (degrees) & 1.80 & 1.91 & $<0.001$ & 1.07 & 2.27 & 0.080 & 0.73 & 0.298 \\
\hline \multicolumn{9}{|c|}{ Transverse } \\
\hline Skeletal width (mm) & 1.76 & 2.08 & 0.001 & 1.09 & 2.82 & 0.142 & 0.67 & 0.412 \\
\hline Dentoalveolar width (mm) & 5.03 & 1.66 & $<0.001$ & 4.86 & 1.44 & $<0.001$ & 0.17 & 0.736 \\
\hline Intermolar angle (degrees) & 20.73 & 5.06 & $<0.001$ & 9.22 & 6.18 & $<0.001$ & 11.51 & $<0.001$ \\
\hline
\end{tabular}

Boldface indicates significant $(p<0.05)$ change over time within and between groups.

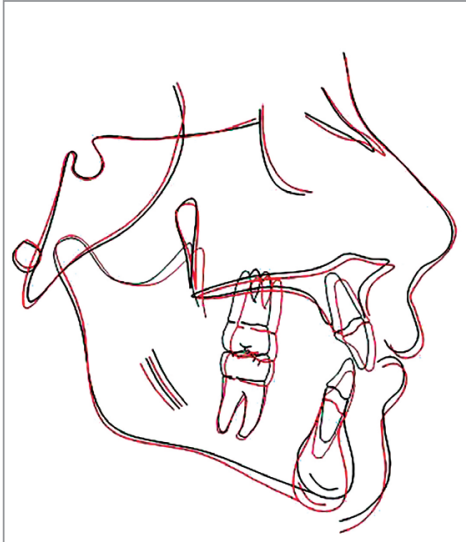

A

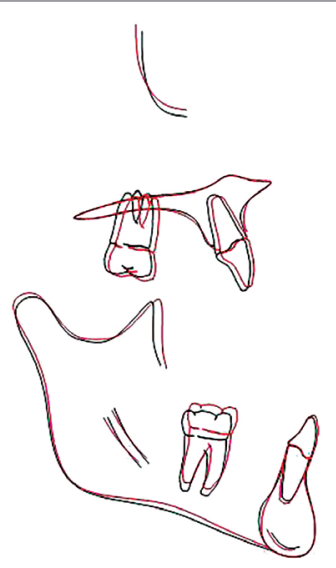

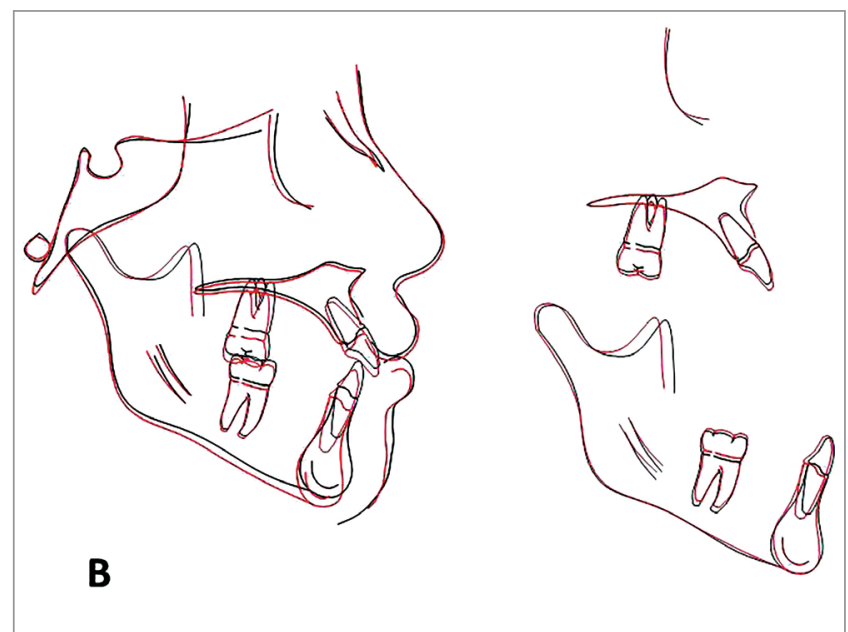

Figure 5 - Cranial base and partial superimpositions showing the morphological changes that occurred in one female who had been treated with RME (A) and another female who had been treated with SME (B).

Table 5 - Magnitude of changes overtime in the transverse relation and the percentage of the amount of transversal increasing related to opening of the screw expander

\begin{tabular}{|c|c|c|c|c|}
\hline \multirow{2}{*}{ Parameters } & \multicolumn{2}{|c|}{ Changes (mean - mm) } & \multicolumn{2}{|c|}{ Width/Screw (\%) } \\
\hline & RME & SME & RME & SME \\
\hline Skeletal width & 1.8 & 1.1 & $22.5 \%$ & $13.7 \%$ \\
\hline $\begin{array}{c}\text { Dentoalveolar } \\
\text { width }\end{array}$ & 5 & 4.9 & $62.5 \%$ & $61.2 \%$ \\
\hline
\end{tabular}

\section{DISCUSSION}

Both treatment approaches were able to make some changes, especially at dental level, but RME generated greater changes. Maxilla showed slightly forward displacement only in RME group (SNperp-A) but based on SNA angle, stayed stable in both groups. Historical samples, i.e. Michigan Growth Standards, ${ }^{9}$ and longitudinal studies in untreated subjects have shown the SNA angle increases less than $0.1 \%$ year and ANS moves forward approximately 
$0.7 \mathrm{~mm} /$ year during childhood ${ }^{10}$ or less than $0.5 \mathrm{~mm} /$ year between 8 and 16 years of age. ${ }^{11,12}$ Lagravere et $\mathrm{a}^{4}$ found nonsignificant anteroposterior skeletal changes in a metaanalysis study about RME. Some studies have shown no anterior displacement of the maxilla ${ }^{13,14}$ but others have shown forward movement of the maxillary complex..$^{15-20}$ The anterior maxillary displacement can be related to the spheno-occipital synchondrosis during maxillary expansion. ${ }^{21}$ The pterygoid process could provide a possible answer to forward movement of A-Point ${ }^{17}$; however, Melsen and Melsen ${ }^{22}$ reported no relationship between the pterygomaxillary region and RME. Also, the maxilla will partially ${ }^{6,18}$ or entirely ${ }^{17}$ return to its original position and, with exception of Hass ${ }^{15}$ - who showed $1.6^{\circ}$ of forward movement of the maxilla after maxillary expansion-, it has been noticed that the amount of anterior movement is small (SNA increased up to $1^{\circ}$ ) and might not be clinically significant.

Interestingly, no significant downward displacement of the maxilla was noticed. When groups were compared, ANS moved down 47\% more $(0.25 \mathrm{~mm}$ difference) and the rotation of the palatal plane angle was three times greater $\left(0.35^{\circ}\right.$ difference) in RME group. Using bonded RME, Sarver and Johnston ${ }^{13}$ reported that the maxilla did not move downward after treatment. Also, the literature has demonstrated, immediately after expansion, a downward maxillary displacement and extrusion of the supporting teeth. ${ }^{14,15,17,23,24}$ The downward movement of the maxilla is claimed due to the disposition of the maxillocraniofacial sutures. ${ }^{6}$ Basciftci and Karaman ${ }^{25}$ found that PNS moved down more than ANS, but Silva Filho et $\mathrm{a}^{14}$ reported that ANS displaced downward more than PNS after RME. Short-term vertical skeletal changes have little, if any, clinical significance.

Maxillary expansion treatment produced backward rotation of the mandible. The mandibular plane angle was increased significantly only in RME group. Comparing RME group to SME group, the SNB angle decreased five times more $\left(-0.47^{\circ}\right.$ compared to $\left.-0.09^{\circ}\right)$ and the MPA increased 1.6 times more. The greater increase in the MPA in RME group may be attributed to the bigger downward displacement of the palatal plane in this group and more buccal tipping. The literature has shown increase in the MPA for RME group and no changes for SME group. ${ }^{4,14,17-19}$ On the other hand, some studies have shown no backward rotation of the mandible..$^{13,16,25}$ Using Haas-type expander, Chang et $\mathrm{al}^{26}$ showed no changes between RME and control groups related to the vertical mandibular position. Some studies consider the vertical changes temporary. ${ }^{26,27}$

Due to treatment, maxilla was expanded transversally. Apical base was increased only in RME group and at bone crest level, both groups experienced expansion. Transversally the maxilla became larger only $2 \%$ at apical level and 63\% at alveolar crest level more in RME group compared to SME group. Previous studies have shown maxillary expansion at apical and alveolar leve ${ }^{28,29}$ and others have shown transversal changes just at alveolar level..$^{28,30,31}$ Greater effect at alveolar level can be explained by lateral rotation of the maxillary halves and lateral bending of alveolar crests with an inclination of the molars towards the buccal segment. ${ }^{11,32}$

Intermolar angle increased due to maxillary expansion. RME group showed two times more buccal tipping than SME group. Buccal tipping has been reported as a common side effect in both $\mathrm{SME}^{16}$ and $\mathrm{RME}^{6,17,28,29}$ and can lead to root resorption. ${ }^{23}$ Comparing slow and rapid maxillary expansion, Martina et $\mathrm{al}^{33}$ did not find buccal tipping related to the slow expansion group. To reduce tipping, authors have used bonded $\mathrm{d}^{34,35}$ or occlusal splint. ${ }^{15,32}$ Tipping can be due to a lateral rotation of the maxillary halves with a fulcrum close to the frontomaxillary suture presenting a triangular expansion pattern. ${ }^{17,29}$ and lateral bending of alveolar crests with an inclination of the molars towards the buccal segment. ${ }^{28,30,31}$ However, RME leads to greater accumulation of force that dissipates a greater amount of anchoring teeth resulting in more sloping. ${ }^{36}$

Maxillary expansion caused more dentoalveolar and buccal tipping than skeletal expansion. Larger increase in the transverse alveolar distance $(62.5 \%$ and $61.2 \%$ of the screw expanding for RME and SME groups, respectively) than apical bone base (22.5\% for the RME group and $13.7 \%$ for SME group related to the total amount of the screw expansion) was observed (Table 5). The greater expansion at dental level compared with the skeletal level has been previously reported. ${ }^{3,4,6,23,30}$

This study is not without limitations. Although some of the measurements showed significant differences, the main problem is the small sample size. The choice among the two expansion modalities relies on clinical experience and attitude of the practitioner, once both methods showed good clinical evidence to expand the maxilla. 


\section{CONCLUSION}

Based on treatment using rapid and slow maxillary expansion, the following conclusions can be drawn:

1. Although both treatment modalities showed molar tipping, RME caused more molar sloping than SME.

2. RME produced skeletal maxillary expansion and SME did not.

3. Both maxillary expansion modalities were eff1cient to promote increase in the transversal dimension at alveolar level but with no difference between groups.

4. RME promoted a forward movement of the maxilla and backward rotation of the mandible.

\section{Authors contribution}

Conception or design of the study: JSP, GLUR. Data acquisition, analysis or interpretation: JSP, HBJ, MB. Writing the article: JSP, HBJ, GLUR. Critical revision of the article: HBJ, AL, GLUR. Final approval of the article: GLUR. Overall responsibility: GLUR.

\section{REFERENCES}

1. Proffit WR, Fields HW Jr, Moray LJ. Prevalence of malocclusion and orthodontic treatment need in the United States: estimates from the NHANES III survey. Int J Adult Orthodon Orthognath Surg. 1998;13(2):97-106.

2. Arvystas MG. The rationale for early orthodontic treatment. Am J Orthod Dentofacial Orthop. 1998:113(1):15-8.

3. Lagravère MO, Major PW, Flores-Mir C. Skeletal and dental changes with fixed slow maxillary expansion treatment: a systematic review. J Am Dent Assoc. 2005 Feb;136(2):194-9

4. Lagravère MO, Heo G, Major PW, Flores-Mir C. Meta-analysis of immediate changes with rapid maxillary expansion treatment. J Am Dent Assoc. 2006 Jan;137(1):44-53.

5. Huynh T, Kennedy DB, Joondeph DR, Bollen AM. Treatment response and stability of slow in macaca mulatta. Am J Orthod 1978:73:1-23.

6. Haas AJ. Palatal expansion: just the beginning of dentofacial orthopedics. Am J Orthod. 1970 Mar:57(3):219-55

7. Rosset A, Spadola L, Ratib O. OsiriX: an open-source software for navigating in multidimensional DICOM images. J Digit Imaging. 2004 Sept;17(3):205-16.

8. Dalhberg G. Statistical methods for medical and biological students. New York: Interscience; 1940

9. Riolo ML, Moyers RE, MCNamara JA, Hunter WS. An atlas of craniofacial growth: cephalometric standards from University School Growth Study, The University of Michigan. Ann Arbor (MI): University of Michigan; 1974.

10. Buschang PH, Martins J. Childhood and adolescent changes of skeletal relationships. Angle Orthod. 1998 June;68(3):199-206; discussion 207-8.

11. Baumrind S, Korn EL, Ben-Bassat Y, West EE. Quantitation of maxillary remodeling. 1. A description of osseous changes relative to superimposition on metallic implants. Am J Orthod Dentofacial Orthop. 1987 Jan;91(1):29-41.

12. Iseri H, Solow B. Growth displacement of the maxilla in girls studied by the implant method. Eur J Orthod. 1990 Nov;12(4):389-98.

13. Sarver DM, Johnston MW. Skeletal changes in vertical and anterior displacement of the maxilla with bonded rapid palatal expansion appliances. Am J Orthod Dentofacial Orthop. 1989 June;95(6):462-6.

14. Silva Filho OG, Villas Boas MC, Capelozza Filho L. Rapid maxillary expansion in the primary and mixed dentitions: a cephalometric evaluation. Am J Orthod Dentofacial Orthop. 1991 Aug;100(2):171-9.

15. Haas AJ. Rapid expansion of the maxillary dental arch and nasal cavity by opening the midpalatal suture. Angle Orthod 1961;31(2):73-90

16. Hicks EP. Slow maxillary expansion: a clinical study of the skeletal versus dental response to low-magnitude force. Am J Orthod. 1978 Feb;73(2):121-41.

17. Wertz RA. Skeletal and dental changes accompanying rapid midpalatal suture opening. Am J Orthod. 1970 Juyl; 58(1):41-66

18. Akkaya S, Lorenzon S, Uçem TT. A comparison of sagittal and vertical effects between bonded rapid and slow maxillary expansion procedures. Eur J Orthod. 1999 Apr:21(2):175-80.

19. Chung $\mathrm{CH}$, Font B. Skeletal and dental changes in the sagittal, vertical, and transverse dimensions after rapid palatal expansion. Am J Orthod Dentofacial Orthop. 2004 Nov:126(5):569-75.

20. Gautam P, Valiathan A, Adhikari R. Stress and displacement patterns in the craniofacial skeleton with rapid maxillary expansion: a finite element method study. Am J Orthod Dentofacial Orthop. 2007 July;132(1):5.e1-11

21. Gardner GE, Kronman JH. Cranioskeletal displacement caused by rapid palatal expansion in the rhesus monkey. Am J Orthod. 1971 Feb;59(2):146-55.

22. Melsen B, Melsen F. The postnatal development of the palatomaxillary region studies on human autopsy material. Am J Orthod. 1982 Oct;82(4):329-42.

23. Haas AJ. The treatment of maxillary deficiency by opening the midpalatal suture Angle Orthod. 1965 July;35(3):200-17.

24. Chung $\mathrm{CH}$, Font B. Skeletal and dental changes in the sagittal, vertical, and transverse dimensions after rapid palatal expansion. Am J Orthod Dentofacial Orthop. 2004 Nov:126(5):569-75.

25. Basciftci FA, Karaman Al. Effects of a modified acrylic bonded rapid maxillary expansion appliance and vertical chin cap on dentofacial structures. Angle Orthod. 2002 Feb;72(1):61-71

26. Chang JY, McNamara JA Jr, Herberger TA. A longitudinal study of skeletal side effects induced by rapid maxillary expansion. Am J Orthod Dentofacial Orthop. 1997 Sept:112(3):330-7.

27. Haas AJ. Long-term posttreatment evaluation of rapid palatal expansion. Angle Orthod. 1980 July:50(3):189-217.

28. Podesser B, Williams S, Crismani AG, Bantleon HP. Evaluation of the effects of rapid maxillary expansion in growing children using computer tomography scanning: a pilot study. Eur J Orthod. 2007 Feb;29(1):37-44

29. Weissheimer A, Menezes LM, Mezomo M, Dias DM, Lima EM, Rizzatto SM. Immediate effects of rapid maxillary expansion with Haas-type and hyrax-type expanders: a randomized clinical trial. Am J Orthod Dentofacial Orthop. 2011 Sept;140(3):366-76

30. Garrett BJ, Caruso JM, Rungcharassaeng K, Farrage JR, Kim JS, Taylor GD. Skeletal effects to the maxilla after rapid maxillary expansion assessed with cone-beam computed tomography. Am J Orthod Dentofacial Orthop. 2008 July:134(1):8-9

31. Corbridge JK, Campbell PM, Taylor R, Ceen RF, Buschang PH. Transverse dentoalveolar changes after slow maxillary expansion. Am J Orthod Dentofacial Orthop. 2011 Sept;140(3):317-25

32. Bell RA. A review of maxillary expansion in relation to rate of expansion and patient's age. Am J Orthod. 1982 Jan;81(1):32-7.

33. Martina R, Cioffi I, Farella M, Leone P, Manzo P, Matarese G, et al. Transverse changes determined by rapid and slow maxillary expansion--a low-dose CTbased randomized controlled trial. Orthod Craniofac Res. 2012 Aug:15(3):159-68

34. Kiliç N, Kiki A, Oktay H. A comparison of dentoalveolar inclination treated by two palatal expanders. Eur J Orthod. 2008 Feb;30(1):67-72

35. Sarver DM, Johnston MW. Skeletal changes in vertical and anterior displacement of the maxilla with bonded rapid palatal expansion appliances. Am J Orthod Dentofacial Orthop. 1989 June:95(6):462-6

36. Isaacson RJ, Ingram AH. Forces produced by maxillary expansion. II. Forces produced during treatment. Angle Orthod. 1964;34(4):261-70. 